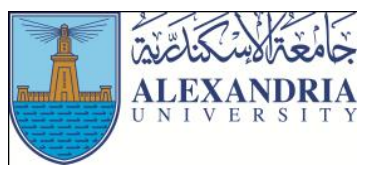

Journal of Applied Sports Science

June 2016, Volume 6, No. 2

www.jass.alexu.edu.eg

\title{
Evaluation of Hammer Throw Technique for Faculty of Physical Education Students using DartFish Technology
}

\author{
Saad Fathallah Mohamed Elalem ${ }^{1}$ \\ ${ }^{1}$ Lecturer at Track and Field Events Training Department, Faculty of Physical Education for Men, Alexandria University
}

\begin{abstract}
Hammer throw Competition is considered one of the most complex throwing Competitions in terms of performance technique and the learning difficulties, therefor using the latest methods and technological means and all possible effectors is required during the learning process. This study aims to evaluate of Hammer Throw Technique for Faculty of Physical Education Students using DartFish Technology. The researcher used the experimental method on a sample of 45 students. They were divided into two groups, a control group which consisted of 25 students who used the traditional program in learning the hammer throw, while the other one is the experimental group which consisted of 20 students who learned the hammer throw by evaluation Technique using DartFish Software Team Pro 4 through three cameras (60 Frame/sec). Finally the results showed that the proposed learning program using DartFish to evaluate the Technique, improved the Technique and distance by developing the single and double support phases times, turn velocity and release in the hammer throw Competition for the students of the Faculty of Physical Education for Boys, Alexandria University.
\end{abstract}

Keywords: Hammer Throw Competition, DartFish application, Technique Evaluation

\section{Introduction}

$\mathrm{T}$ The Hammer throw is one of the complex Competitions due to its Technique, which requires utilizing the forces of various parts in the body and movements harmony. The main aim of which is to throw the hammer away as far as possible without infracting the rules of the Competition. The main aim of which is to throw hammer away as far as possible without infracting the rules of the Competition. The right technique depends on reaching the maximum velocity with the hammer at releasing. The movement begins with preliminary swings followed by three or four turns, where the player turns with the hammer in synchronized manner. While swinging and turns the hammer's speed increases gradually until releasing. (22:228), (23:127), (2:69)

The Hammer throw Competition is considered one of the most complex throwing Competitions in terms of technique and the learning difficulty. (21:56) as it requires compatibility of body mass with the tensile strength resulting from the turns, so the coaches have to take their time in teaching by dividing the Competition components into separate parts to practice each of them separately preparing to perform them again combined as one unit, and then divided once again periodically. (9:4113) (24:71) the player's success is noticed during the various trainings and educational exercises from the beginning of learning until reaching the high levels. (15:111)

The researcher noticed the lack of hammer throw players in most of the clubs of Alexandria Governorate, Egypt, because of the difficulty of this Competition and the lack of suitable fields for the game. Although the hammer throw Competition is taught to the students of the Faculty of Physical Education for Boys, Alexandria University, the Technique and distance are very weak compared to the other throwing Competitions. The researcher made Exploratory Study on 295 of the second grade students of the academic year 2014/2015, in order to identify the hammer throw distance. The results concluded the distance $16.522 \pm 4.026$ meters. The most notable reason for the weak of distance of those students is great learning difficulty in the hammer throw, and that led to the low Technique and distance.

Therefore, the researcher proposed an educational program depends on evaluating the Technique phases during teaching the hammer throw Competition using DartFish application, as it is considered the most modern application of analyzing Technique. It is an effective and integrated application for analyzing videos using the tools and features that enable direct analysis and evaluation of 
the performance through the teaching and training phases and during the sports competitions. (8)

Technique preparation is the main factor for enhancing of the performance level by teaching and developing the performance method which appears through the optimal performance of the technique, so the coaches had to improve the technique by using the latest methods and ways that improve the level. $(5: 418)$

Education is more effective when more senses are used in the educational process. This explains the increased interest in using the learning Instruments in learning the motor skills. (17:163) therefore it is important to learn the sport technique gradually using all the effects that serve the required coordination and speed of movement, and avoiding the errors by using the re-presenting method combined with clarification and explanation. (26:44), the most important means of learning using computer and modern technology, which contribute to achieve the interaction of the learner and enables individual education that commensurate with the characteristics of learners and provides a learning environment with a variety of alternatives. (16:529)

This was the main reason for the researcher to conduct and implement an learning program depends on evaluating the Technique phases during learning the hammer throw Competition using DartFish Technology for the students of the Faculty of Physical Education for Boys, Alexandria University.

\section{Research Aim}

Identifying the impact of using DartFish Technology during the learning program to improve the performance of the hammer throw Competition for the students of the Faculty of Physical Education for Boys, Alexandria University.

\section{Research Hypothesis}

The learning program using DartFish Technology improves the performance of the hammer throw Competition for the students of the Faculty of Physical Education for Boys, Alexandria University.

\section{Research Procedures}

The researcher used the experimental method that include two groups (experimental and control) using postmeasurement, during the academic year 2015/2016 in the field of the Faculty of Physical Education for Boys, Alexandria University. He used three Panasonic video cameras (60 Frame/sec), the kinetic analysis application (DartFish Software Team Pro 4), laptop, display device (Data show), and educational program consisting of 10 educational units.

\section{Research Sample}

The research sample consisted of (45) students (19.36 \pm 0.750 years) of one studying grade which divided into two groups (experimental 20 students) who used the proposed learning program, (control 25 students) used the traditional learning program (implemented on students at the faculty). The statistical characterization of the sample is shown in table (1)

Table (1)

Statistical of the sample $(n=45)$

\begin{tabular}{|c|c|c|c|c|c|c|}
\hline Variables & Min & Max & Mean & SD & Skewness & Kurtosis \\
\hline Age (year) & 18 & 21 & 19.36 & 0.750 & 1.011 & 0.548 \\
\hline Length $(\mathrm{cm})$ & 166 & 193 & 177.41 & 7.089 & 0.185 & -0.661 \\
\hline Weight $(\mathrm{kg})$ & 59 & 105 & 78.35 & 11.235 & 0.345 & -0.381 \\
\hline
\end{tabular}

Table (1) shows the lowest and highest values, the arithmetic mean and the standard deviation, and it shows that all Skewness, Kurtosis coefficients are confined between $( \pm 3)$, and that shows the compatibility between values and the homogeneity of the research sample before the main study.

\section{Exploratory Study}

The study was conducted on $05 / 12 / 2015$ on a sample of three students from the research community and outside the basic sample in order to regulate and control the imaging of Technique process and determine where to place the cameras, the results clarified where to place each camera (back, side, top) in the middle of motion range, where the back and side cameras are located for about (6 $\mathrm{m})$, columnar to the final edge of the throwing circle with $(1.10 \mathrm{~m})$ height, and range for imaging is $(7 \mathrm{~m})$ to cover the variables of release, while the upper camera is situated at a height of $(4.5 \mathrm{~m})$, and the range of imaging is $(5 \mathrm{~m})$ to cover the variables during the turn in the hammer release, $(1.22 \mathrm{~m})$ ruler was captured in horizontal and vertical positions to determine the scale. 
Basic Study: The research was conducted on the sample in a period from $1 / 5$ to $6 / 12 / 2015$ according to the following operational steps: basic and physical measurements were conducted in a period from 1-5/11/2015 to identify the homogeneity and equivalence of the two groups of the research as shown in table (2).

\section{I- Pre-measurement}

Table (2)

$\mathrm{T}$ test to the experimental and control group in the basic and physical measurements before applying the research

\begin{tabular}{|c|c|c|c|c|c|c|}
\hline \multirow[t]{2}{*}{ Variables } & \multicolumn{2}{|c|}{$\begin{array}{c}\text { Experimental } \\
\mathrm{n}=20\end{array}$} & \multicolumn{2}{|c|}{$\begin{array}{c}\text { Control } \\
\mathrm{n}=25\end{array}$} & \multirow{2}{*}{$\begin{array}{l}\text { "T" } \\
\text { test }\end{array}$} & \multirow[t]{2}{*}{ Sig. } \\
\hline & mean & SD & mean & SD & & \\
\hline Age (year) & 19.45 & 0.826 & 19.29 & 0.690 & 0.69 & 0.492 \\
\hline Length $(\mathrm{cm})$ & 179.00 & 7.108 & 176.08 & 6.940 & 1.37 & 0.177 \\
\hline Weight (kgm) & 82.00 & 10.887 & 75.36 & 12.482 & 1.92 & 0.062 \\
\hline High jump $(\mathrm{cm})$ & 44.55 & 11.399 & 45.18 & 10.103 & 0.19 & 0.850 \\
\hline Long jump (cm) & 241.35 & 32.804 & 242.83 & 28.664 & 0.16 & 0.874 \\
\hline Throwing a $3 \mathrm{~kg}$ ball forward $(\mathrm{m})$ & 10.88 & 1.620 & 10.11 & 1.537 & 1.58 & 0.121 \\
\hline Throwing a 3kg ball backward (m) & 11.56 & 2.385 & 11.61 & 2.258 & 0.08 & 0.941 \\
\hline $30 \mathrm{~m}$ sprint $(\mathrm{sec})$ & 4.65 & 0.327 & 4.85 & 0.410 & 1.76 & 0.086 \\
\hline
\end{tabular}

Table (2) shows that there were no significant differences for the " $t$ " test value between the experimental and control group in the basic and physical measurements, which confirm the equivalence between the two groups before applying the research.

\section{II- Learning program:}

The traditional Learning program of the hammer throw, which was applied on the control group for one month was divided to (10units) according to the time plan of the semester, each unit takes (90min), and includes (20min) for warm up and physical preparation, which consists of light running on the turf and performing general exercises for all parts of the body, (60min) for Technique where the skill exercises is performed as well as Technique Learning for the hammer throw Competition, and (10min) for rest.

The proposed program was applied on the experimental group during the lecture on the same conditions, procedures and duration applied to the control group, where it took a period of time from 12/11 to 6/12/2015, taking into consideration the research articles and literature review of hammer throw (3), (5), (10), (11), (14), (21). The program contains a variety of learning exercises and skill parts, Attachment (1), with continuous learning and evaluation of Technique by immediate feedback using DartFish application, Attachment (2).

\section{III- Post-measurement}

Post-measurement was conducted on 6/12/2015 by imaging the Technique of hammer throw for both groups of the research, where the cameras were placed according to the results of the Exploratory study as shown in Figure (1). All the sample attempts for individuals were recorded by which three attempts for each student, to choose the best attempt with the longest distance of throwing the hammer for motor analysis using DartFish Software Team Pro 4, to extract the biomechanical variables of Technique to the hammer throw, to process the statistical data.

Figure (1)

the locations and dimensions of the cameras during imaging the Technique of the hammer throw

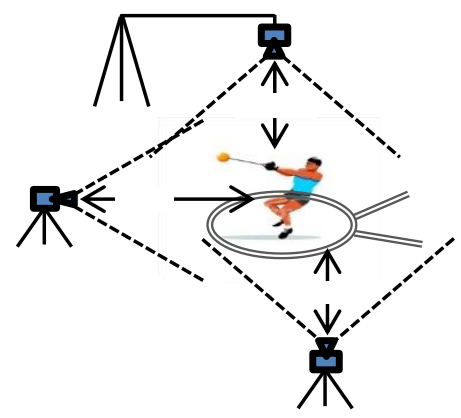


Statistical Processors: arithmetic mean, standard deviation, percentage, Skewness and kurtosis coefficient

\section{Results} and $\mathrm{T}$ test.

Table (3)

$\mathrm{T}$ test to the experimental and control group for the supports Duration and knee angle in the hammer throw Competition

\begin{tabular}{|c|c|c|c|c|c|c|c|}
\hline \multirow[t]{2}{*}{ Variables } & \multicolumn{2}{|c|}{$\begin{array}{c}\text { Experimental } \\
\mathrm{n}=20\end{array}$} & \multicolumn{2}{|c|}{$\begin{array}{c}\text { Control } \\
\mathrm{n}=25\end{array}$} & \multirow{2}{*}{$\begin{array}{c}\text { Difference } \\
\text { Percentage } \\
\%\end{array}$} & \multirow{2}{*}{$\begin{array}{l}\text { "T" } \\
\text { Test }\end{array}$} & \multirow[t]{2}{*}{ Sig. } \\
\hline & mean & SD & mean & SD & & & \\
\hline Single support time (SST) (s) & 0.47 & 0.07 & 0.41 & 0.11 & 14.63 & $2.12 *$ & 0.040 \\
\hline double support time (DST) and release (s) & 0.44 & 0.07 & 0.61 & 0.15 & 27.87 & $4.71 * *$ & 0.000 \\
\hline Total time for turn and release $(\mathrm{sec})$ & 1.19 & 0.16 & 1.34 & 0.16 & 11.19 & $3.07 * *$ & 0.004 \\
\hline Knee angle during Single support (degree) & 136.75 & 9.633 & 136.16 & 9.754 & 0.43 & 0.20 & 0.843 \\
\hline
\end{tabular}

Table (3) shows significant differences between the (11.19\%, 27.87\%), the Knee angle during Single support experimental and control group at supports Duration was $(0.43 \%)$ in favor to the experimental group. during turn. The percentage of difference ranged between

Table (4)

$\mathrm{T}$ test to the experimental and control group in angular displacement and average angular velocity of the Shoulders and hammer during supports in the hammer throw Competition

\begin{tabular}{|c|c|c|c|c|c|c|c|c|}
\hline \multirow{2}{*}{\multicolumn{2}{|c|}{ Variables }} & \multicolumn{2}{|c|}{$\begin{array}{c}\text { Experimental } \\
n=20\end{array}$} & \multicolumn{2}{|c|}{$\begin{array}{c}\text { Control } \\
n=25\end{array}$} & \multirow{2}{*}{$\begin{array}{c}\text { Difference } \\
\text { Percentage } \\
\%\end{array}$} & \multirow{2}{*}{$\begin{array}{l}\text { "T" } \\
\text { test }\end{array}$} & \multirow[t]{2}{*}{ Sig. } \\
\hline & & mean & SD & mean & SD & & & \\
\hline \multirow{2}{*}{$\begin{array}{l}\text { Angular displacement } \\
\text { during supports (angle) }\end{array}$} & $\begin{array}{c}\text { Shoulders } \\
\text { Twisting }\end{array}$ & 182.98 & 39.530 & 145.65 & 45.632 & 25.63 & $2.89 * *$ & 0.006 \\
\hline & $\begin{array}{l}\text { Hammer } \\
\text { turn }\end{array}$ & 166.14 & 32.346 & 118.63 & 41.108 & 40.08 & $4.09 * *$ & 0.000 \\
\hline \multirow{2}{*}{$\begin{array}{l}\text { Average angular } \\
\text { velocity during } \\
\text { supports (angle) }\end{array}$} & $\begin{array}{c}\text { Shoulders } \\
\text { Twisting }\end{array}$ & 385.50 & 53.599 & 355.39 & 62.423 & 8.47 & 1.71 & 0.094 \\
\hline & $\begin{array}{l}\text { Hammer } \\
\text { turn }\end{array}$ & 353.00 & 55.684 & 288.49 & 73.356 & 22.36 & $3.25 * *$ & 0.002 \\
\hline
\end{tabular}

Table (4) shows significant differences between the during supports. The percentage of difference ranged experimental and control group at angular displacement between $(8.47 \%, 40.08 \%)$ in favor to the experimental and average angular velocity of the Shoulders and hammer group.

Table (5)

$\mathrm{T}$ test to the experimental and control group for hammer and variables during release in the hammer throw Competition

\begin{tabular}{|c|c|c|c|c|c|c|c|c|}
\hline \multicolumn{2}{|l|}{ Variables } & \multicolumn{2}{|c|}{$\begin{array}{l}\text { Experimental } \\
\mathrm{n}=20\end{array}$} & \multicolumn{2}{|c|}{$\begin{array}{l}\text { Control } \\
\mathrm{n}=25\end{array}$} & \multirow{3}{*}{$\begin{array}{c}\text { Difference } \\
\text { Percentage } \\
\%\end{array}$} & \multirow{3}{*}{$\begin{array}{c}\text { "T" } \\
\text { test }\end{array}$} & \multirow{3}{*}{$\begin{array}{c}\text { Sig. } \\
0.329\end{array}$} \\
\hline & & \multirow{2}{*}{$\begin{array}{c}\text { mean } \\
2.28\end{array}$} & \multirow{2}{*}{\begin{tabular}{c|} 
SD \\
1.618
\end{tabular}} & \multirow{2}{*}{$\begin{array}{c}\text { Mean } \\
2.82 \\
\end{array}$} & \multirow{2}{*}{\begin{tabular}{c|} 
SD \\
1.999
\end{tabular}} & & & \\
\hline \multirow{3}{*}{$\begin{array}{l}\text { Hammer velocity in the beginning of turn } \\
\qquad(\mathrm{m} / \mathrm{s})\end{array}$} & Vertical & & & & & & & \\
\hline & Horizontal & 8.73 & 1.391 & 5.90 & 1.507 & 47.97 & $6.47 * *$ & 0.000 \\
\hline & Resultant & 9.15 & 1.390 & 6.93 & 0.846 & 32.03 & $6.60 * *$ & 0.000 \\
\hline \multirow{3}{*}{ Hammer Velocity at release $(\mathrm{m} / \mathrm{s})$} & Vertical & 9.68 & 2.273 & 7.60 & 2.475 & 27.37 & $2.89 * *$ & 0.006 \\
\hline & Horizontal & 12.10 & 2.532 & 8.84 & 2.392 & 36.88 & $4.43 * *$ & 0.000 \\
\hline & Resultant & 15.60 & 2.832 & 11.94 & 2.243 & 30.74 & $4.85^{* *}$ & 0.000 \\
\hline \multicolumn{2}{|l|}{ height of Release (m) } & 1.70 & 0.164 & 1.73 & 0.208 & 1.73 & 0.58 & 0.566 \\
\hline \multicolumn{2}{|l|}{ angle of release (degree) } & 37.98 & 6.393 & 39.72 & 12.301 & 4.38 & 0.57 & 0.569 \\
\hline \multicolumn{2}{|l|}{ Elbow angle during release (degree) } & 159.98 & 20.514 & 141.82 & 21.523 & 12.80 & $22.85 * *$ & 0.007 \\
\hline
\end{tabular}


Table (5) shows significant differences between the experimental and control group at Hammer velocity and variables during release. The percentage of difference ranged between $(1.73 \%, 47.97 \%)$ in favor to the experimental group.

Table (6)

$\mathrm{T}$ test to the experimental and control group in the Hammer distance in the hammer throw Competition

\begin{tabular}{|c|c|c|c|c|c|c|c|}
\hline \multirow{2}{*}{ Variables } & \multicolumn{2}{|c|}{$\begin{array}{c}\text { Experimental } \\
\mathrm{n}=20\end{array}$} & \multicolumn{2}{c|}{$\begin{array}{c}\text { Control } \\
\mathrm{n}=25\end{array}$} & $\begin{array}{c}\text { Difference } \\
\text { percentage } \\
\%\end{array}$ & $\begin{array}{c}\text { "T" } \\
\text { Test }\end{array}$ & Sig. \\
\cline { 2 - 6 } & mean & SD & mean & SD & & \\
\hline distance $(m)$ & 24.40 & 4.489 & 17.40 & 3.884 & 40.23 & $5.61 * *$ & 0.000 \\
\hline
\end{tabular}

Table (6) shows significant differences between the experimental and control group at the Hammer distance. The percentage of difference was $(40.23 \%)$ in favor to the experimental group.

\section{Discussion}

It is clear from tables (3), (4) that Total time for turn and release for the experimental group was $1.19 \mathrm{sec}$. with $11.19 \%$ less than the control, and (DST) and release was less by $27.87 \%$, while (SST) was greater in the experimental than the control because the experimental group members performed a complete turn, where the Angular displacement during supports for Shoulders was 182.98 degrees with 385.50 degrees for Average angular velocity, whereas the control was 145.65 degrees with 355.39 degrees for the Average angular velocity and the difference percentage was $25.63 \%$. The Angular displacement during supports to the hammer was 166.14 degrees for the experimental while the control was 145.65 degrees and the difference percentage was $40.08 \%$ in favor to the experimental group.

The results were due to instant evaluation for the Technique of the experimental group using DartFish application. The experimental performed the turn at high speed in a short time during turn and release, while the (DST) and release a longer time for the control to overcome the incomplete turn, which in turn led to an increase in (DST) and release. The knee angle of (SS) leg of the experimental was better by $0.43 \%$ through a large bend of the knee, which works on balance, stability and control in the hammer through the turn. Bartenz (2008) pointed that the lowest level of the body must be maintained during turn, and then the legs have to be fully expanded during release. $(3: 484)$

During the (DS) duration, the horizontal and vertical velocity increase. To achieve the maximum effectiveness, the horizontal velocity must be improved during this duration; the Vertical velocity can also be improved. During the phases of (SS) of turn, the player can increase the Vertical velocity, if he had to. (2:78)
It is clear from table (5) that the Resultant velocity of the hammer at the beginning of turn for the experimental group $(9.15 \mathrm{~m} / \mathrm{s})$ was greater than the control $(6.93 \mathrm{~m} / \mathrm{s})$ with difference percentage $32.03 \%$, which shows that preliminary swinging and preparing for turn were better at high velocity in the experimental, while there was fluctuation in the hammer path in the control through increasing the vertical velocity of the hammer by $19.50 \%$, whereas there was a difference by $47.97 \%$ in the horizontal velocity of the hammer in favor to the experimental.

The resultant velocity of the hammer at release was $15.60 \mathrm{~m} / \mathrm{s}$. in the experimental group which was greater than the control which was $11.94 \mathrm{~m} / \mathrm{s}$. with difference of $30.74 \%$, and an increase in horizontal velocity with difference of $36.88 \%$ and vertical velocity with difference at $27.37 \%$, and this shows the high velocity of the hammer during release in the experimental. The increase in hammer velocity from starting the turn until release was $6.45 \mathrm{~m} / \mathrm{s}$ for the experimental which was greater than the control with $5.01 \mathrm{~m} / \mathrm{s}$ and this indicates the increased velocity during turn. In order to overcome the little velocity of the control, the angle and height of Release were increased with 39.72 degrees, while it was 37.98 degrees for the experimental with difference of $4.38 \%$ in favor to the control.

The angular velocity of the hammer increases gradually during the turn due to the increase that occurs during supports. We would find that the half of the diameter increases in (SS), and decreases in the (DS) and has an effect on the velocity of the hammer. (18) The relationship between initial and final angular velocities is one of the important factors in the throw movement. Throw technique is effective when a player increases the acceleration from one phase to another to enhance the angular velocity, which transmits in turn to the hammer velocity. (3:474)

Turns are the best opportunity to increase the horizontal velocity. The vertical velocity is also a very important component of the Resultant velocity of the hammer. Andreas (2009) Holds that focusing on (DS) phase may be 
misplaced in increasing the hammer velocity. This does not mean that (DS) phase is not important, but there other aspects work on increasing it when throwing and releasing. (2) while Dapena, J. (1989) suggests increasing the hammer velocity generally and effectively during (DS) phases for throwing, because the hammer velocity increases between the high and low points of its orbit which almost coincides with the start and the end of (DS) phase respectively. (6) Hammer velocity can be increased in (DS) and (SS) phase during turns by increasing the vertical velocity and decreasing half of the diameter of the hammer. (19)

The increase in hammer velocity is associated with generating intention for turn around the horizontal axis which means that the increase in velocity is vertical velocity and a little part to the horizontal velocity for the hammer that increase effectively during (DS) more than (SS). However this only happens when the player turns very slowly, but when he turns quickly it becomes impossible to increase the horizontal velocity at any phase of support. (7) (6)

The velocity generated of turns and the release is resulted from transferring the energy of acceleration to the different parts of the body in the least possible time while reducing the phases of damping during (SS) phase, at the end of (DS) phase, to achieve a high level of required ability during release. (3) The velocity of the hammer release has the effective role in flight distance, which arises from the gained movement and speed through swings and turns. This is linked to a positive relationship with the length of the hammer distance. (26:29)

The Elbow angle during release in the experimental group was 159.98 degrees greater than the control which was 141.82 degrees with difference of $12.8 \%$, and this reflects the proper release in the experimental, this is due to the instant evaluation and errors correction during the phases of Technique. If turn is performed properly, velocity will increase smoothly during turn. Here comes the final acceleration through the extending the joints of the body with pushing with the right leg and concentrating on proper release. (13)

Improvement results in biomechanical variables and Technique led to improving the hammer throw distance with $24.40 \mathrm{~m}$ for the experimental group greater than the control which was $17.40 \mathrm{~m}$ with a difference of $40.23 \%$. Success in hammer throw Competition requires proper biomechanical variables for throwing, which is the player's skill in throwing from optimal angle close to 45 degrees, the proper power, the body mass for balance, the length of half of the diameter of the throwing arm and the velocity during release. (12)
The hammer distance is determined according to release velocity, height and angle of release and air resistance. The hammer Velocity is the most important factor in throwing. The proper release angle to the players ranges from 34 to 44 degree. (3) Some studies have shown that release angle of female players ranged between 29 and 42 degree. However, the angle of 44 degree is optimal for both male and female players. (4) The initial release velocity determines crucial victory or defeat on the competitive level. (20), (18)

The achieved improvement in results is due to using the proposed learning program by instant evaluation for the Technique using the DartFish application on the experimental group that showed efficiency through improving and developing the performance of turn at high velocity in least time, quick release and proper angle. The learning process aims to learn performing various motor skills by the coach through facilitating the various movements avoiding the common mistakes as possible. (25:246)

The skill provided by the coach that has no reaction from the players cannot make any success, because the player's ability to understand the movements depends on the extent of awareness of their details and his response to all audio and visual effects and correcting errors through the learning process. (25:248) learning by using computers and modern technology provides information and opportunities for the learner to let him seek for right solutions by himself, also simulation makes learning more exciting and helps learners to improve their skills, while multiple learning methods make the player more effective and integrated in learning and developing skills and evaluating results. $(16: 551)$

Computer facilities can help in training the champions as to win competitions. It was clear that a lot of the athletes who participated in the 2004 Olympics in ATHENS, and a similar percentage among medal winners in this event have been trained by DartFish company applications. At the 2002 Winter Olympics in Salt Lake City, 45 medals were achieved thanks to those programs that use digital video camera to develop the training, to compare between players performances, to measure the movement time, and to correct the positions taken by each player during performance by comparing between the details of sports movements. (1:18)

According to results discussion, the research hypothesis was validated. The proposed learning program using DartFish Technology improves the performance of the hammer throw Competition for the students of the Faculty of Physical Education for Boys, Alexandria University. 


\section{Conclusions}

1- The proposed learning program using DartFish Technology to evaluate the Technique led to improve supports times, velocity of turn and release in hammer throw Competition for the students of the Faculty of Physical Education for Boys, Alexandria University.

2- The proposed learning program using DartFish Technology to evaluate the Technique led to improve Technique and the hammer throw distance for the students of the Faculty of Physical Education for Boys, Alexandria University.

\section{Recommendations}

1- It is important to implement the proposed learning program using DartFish Technology to evaluate the Technique in teaching hammer throw Competition for the students of the Faculty of Physical Education for Boys, Alexandria University.

2- The instant Evaluation Technique is important during teaching and training complex skills and throw Competitions.

3- Learning programs design for throw Competitions using modern technology and analysis Technique applications.

\section{References}

1- Ahmed Maghraby (2004): DartFish, The Electronic Secret of Sport, Life Magazine, No. 15147, Page 18, Part of Information Technology and E-Commerce.

2- Andreas V. (2009): Reassessing velocity generation in hammer throwing, NSA. by IAAF, 24:4; 71-80.

3- Bartonietz K. (2008): Hammer Throwing: Problems and Prospects, 458 (BIOMECHANICS IN SPORT) Mont Hubbard University of California, Davis, Mont Hubbard, Retrieved on: 29 February 2016

4- Bartonietz, K. (1994): Hammerwurf der Frauen quo vadis? Lehre der Leichtathletik 33 (3) 15-16, 33-34, (4), 18.

5- Bastawissy Ahmed (1997): Track and Field Events (Teaching - Technique - Training), First Edition, Dar AlFikr Al-Araby.

6- Dapena, J. (1989): Some biomechanical aspects of hammer throwing. Athletics Coach, 23 (3), 12-19.

7- Dapena, J. (2007; 2008): Personal Communication. EBERHARD, G. (1990). Model technique analysis sheets for the throwing events Part V: The Hammer Throw. I.A.A.F, New Studies in Athletics, 5 (1), 61-67

8- DartFish: User's Guide for DartFish application, http://www.dartfish.com

9- Gassner G. (1994): The paradoxical nature of the hammer,

4113-4114, throw.www.trackandfieldnews.com/technihque/129Greg

Gassner.pdf.

10- Hildebrand, F. \& Bartonietz, K. (1995): Eine biomechanische Analyse des Hammerwerfens am Beispiel der Technik zweier Werferinnen. In: Schriftenreihe zur angewandten Trainingswissenschaft 3 pp. 45-56. Meyer \& Meyer, Aachen.

11- International Association of Athletics Federations (IAAF) (2009): (Run, Jump, Throw), The Official International Federation for Teaching Athletics.

12- Jermy M. C., Burgess A., Feasey C., Lensen M., Willis C., Tucker A. S., Syme R. W. G. (2014): A variable drag coefficient, spatially extended numerical model of hammer throws and new wind tunnel data on current hammers, Sports Eng (2014) 17:151-164

13- Judge, L. (1999): Teaching the Women's Hammer. Track coach. Summer, (148): 4713-4719.

14- Khalid Wahid Ibrahim (1999): The Effect of Using Rubber Belt for Pelvis and Trunk during the Turn on Technical Performance to Throw the Hammer, Unpublished Master Thesis, Faculty of Physical Education for Boys, Alexandria University.

15- Kolodiy, O., (1985): Training of young Hammer Throwers, Book Division of Track \& Field News, Tafnews Press, U.S.A.

16- Magdy Aziz Ibrahim (2004): Teaching Strategies and Learning Methods, Angelo Egyptian Library.

17- Mohamed Mohamed El-Hamahemy \& Amin ElKhouly (1990): Basics of Creating Physical Education Programs, Dar Al-Fikr Al-Araby.

18- Murofushi, K., Sakurai, S., Umegaki K., Kobayashi K., (2005): Development of a System to Measure Radius of Curvature and Speed of Hammer Head during Turns in Hammer Throw, International Journal of Sport and Health Science Vol.3, 116-128.

19- Murofushi, K.; Sakurai, S.; Umegaki, K. \& Takamatsu,J. (2007): Hammer acceleration due to the thrower and hammer movement patterns. Sports Biomechanics,6 (3), 301-314. 
20- Murofushi, S. (1994): Hammer throw. (pp. 30-52). Tokyo: Baseball Magazine Sha Co., Ltd. (In Japanese)

21- Osama Mohamed Abu-Tabl (1995): The Effect of Improving the Functional Efficiency of the Balance Maintaining Device on the Distance of Hammer Throw, Unpublished Master Thesis, Faculty of Physical Education for Boys, Alexandria University.

22- Paish, W., (1976): Track and Field Athletics, Lepus Books, and Associate Co., of Henry Kimpton Ltd., Edinburgh.
23- Patrov, V., (1985): Hammer Throw Technique and Drills, Book Division of Track \& Field News, Tafnews Press.

24- Pedemonte, J., (1985): A Divice to novice Hammer throwers, Book Division of Track \& Field News, Tafnews Press.

25- Sulayman Aly Hassan, Mohamed Zaky Darwish \& Ahmed Mahmoud El-Khadem (2013): Scientific Analysis of Track and Field, Dar Al-Maaref.

26- Zaky Mohamed Darwish \& Adel Mahmoud AbdelHafez (1994): Encyclopedia of Athletics (Throwing and Compound Events), Dar Al-Maaref. 